\title{
ROLE OF FNAC AS A FIRST LINE INVESTIGATION TO IDENTIFY MALIGNANCIES IN CERVICAL LYMPH NODES
}

KEY WORDS: FNAC, cervical lymph node.

\section{Dr. Pradeep Kumar nagar Dr. Brajendra shakyawal*}

Final year resident doctor, department of pathology, jhalawar medical college,jhalawar

assistant professor, department of pathology, jhalawar medical college, jhalawar *Corresponding Author.

Lymphadenopathy is the commonest clinical presentation encountered in outpatient as well as inpatient department irrespective of age [1].FNAC is a simple, early and rapid diagnostic procedure to identify an etiology in an enlarged lymph node. Objectives of this study were to study role of FNAC in evaluating enlarged cervical lymph nodes, and to categorize malignant cases into primary and metastatic lesions. Total number of cases were 530. Out of which 477 cases were benign/infectious and 53 were malignant. The age of patients in malignant lymph node aspirates ranged from 10 year to 81 year. Out of total 53 malignant cases, 48(90.6\%) cases were metastatic lesions 5 cases $(9.4 \%)$ were lymphoma. Metastasis to lymph node 48 cases $(90.6 \%)$ was more common than primary lymphomas 5 cases $(9.4 \%)$. Present study highlights the importance of FNAC. FNAC is a simple rapid cost effective in diagnosing patients presenting with cervical lymphadenopathy. It also helps to diagnose malignancy in advanced stage patients based on the FNAC diagnosis these cases can be managed on palliative care thereby saving the patient from excision biopsy.

\section{Introduction:}

Lymphadenopathy is the commonest clinical presentation encountered in outpatient as well as inpatient department irrespective of age[1].

It is one of the common clinical presentations in both benign and malignant diseases [2]

FNAC is a simple, early and rapid diagnostic procedure to identify an etiology in an enlarged lymph node. FNAC is a safe, easy and minimally invasive diagnostic procedure which can be performed in the office settings[3].

The procedure is quite effective in diagnosing malignancies in cervical lymph nodes because of easily accessible to subjected for FNAC [4].

Aims and objectives: Role of FNAC in evaluating enlarged cervical lymph nodes, and to categorize malignant cases into primary and metastatic lesions.

\section{Material and method:}

Research design: prospective study

Selection of study population: patients presented with palpable cervical lymphadenopathy referred for cytological evaluation in department of pathology, jhalawar medical college, jhalawar, rajasthan were included.

Duration: the duration of the study was one year (June 2019 to May 2020).Thorough examination of the patient was done and also detailed clinical history was taken.

Standard FNAC procedure was performed by using $5 / 10 \mathrm{ml}$ disposable syringe and 22-23 gauge needle and multiple smears were prepared. Smears fixed in absolute alcohol, were stained with haematoxylin and Eosin ( $\mathrm{H}$ and $\mathrm{E})$ and papnicoloau stains, while air dried smears were stained with May-Grunewald Giemsa (MGG) Stain.

All cytological smears were evaluated for adequacy, cellularity, types of cells, arrangement of cells and nuclear as well as cytoplasmic features. Background was evaluated in all smears for any specific findings like necrosis or presence of mucin.

\section{RESULTS}

Total number of cases were 530. Out of which 477 cases were benign/infectious and 53 were malignant.
The age of patients in malignant lymph node aspirates ranged from 10 year to 81 year. There were 42 males $(79.3 \%)$ and 11 females $(20.7 \%)$. The male to female ratio was $4.8: 1$.

Out of total 53 malignant cases, $48(90.6 \%)$ cases were metastatic lesions 5 cases $(9.4 \%)$ were lymphoma. Metastasis to lymph node 48 cases $(90.6 \%)$ was more common than primary lymphomas 5 cases $(9.4 \%)$.

Squamous cell carcinoma (75.4\%) was the most common morphological type diagnosed on cytology in metastatic lymph nodes followed by adenocarcinoma.

Among primary lymphomas Non Hodgkin lymphoma was seen in 3 cases $(60 \%)$ and Hodgkin lymphoma in 2 cases (40\%).

Table -1 Distribution of lesions in malignant cervical lymphadenopathy $(n=53)$

\begin{tabular}{|c|c|c|}
\hline Cytological diagnosis & No. Of cases & Percentage \\
\hline $\begin{array}{c}\text { Metastatic squamous cell } \\
\text { carcinoma. }\end{array}$ & 40 & 75.4 \\
\hline Metastatic adenocarcinoma & 7 & 13.2 \\
\hline $\begin{array}{c}\text { Metastatic papillary carcinoma } \\
\text { of thyroid }\end{array}$ & 1 & 1.88 \\
\hline Hodgkin lymphoma & 2 & 3.77 \\
\hline Non Hodgkin lymphoma & 3 & 5.66 \\
\hline
\end{tabular}

Table -2 Distribution of lesions in malignant cervical Lymphadenopathy

\begin{tabular}{|c|c|c|}
\hline $\begin{array}{c}\text { Cytological } \\
\text { diagnosis }\end{array}$ & No. Of cases & Percentage \\
\hline Metastatic lesions & 48 & 90.6 \\
\hline Lymphomas & 5 & 9.4 \\
\hline
\end{tabular}

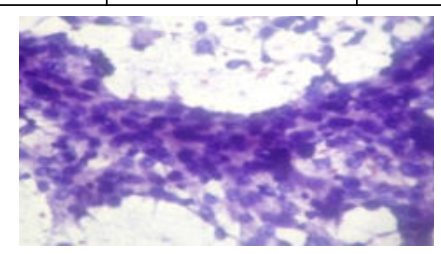

Figure: 1. FNAC Smear of metastatic deposits of squamous cell carcinoma in lymph node showing Squamoid type tumourcells 


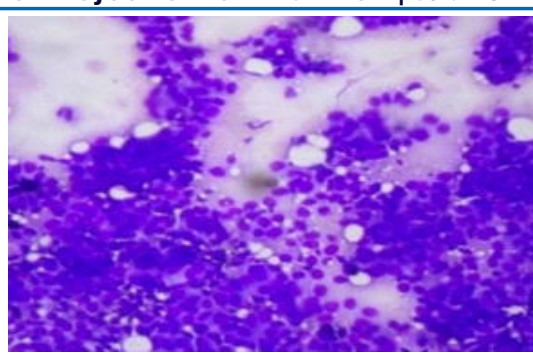

Figure: 2. FNAC Smear of metastatic deposits of adenocarcinoma in lymph node showing: cluster of malignant cells forming acinar pattern

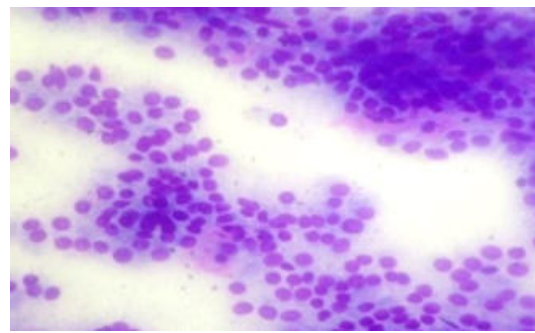

Figure: 3. FNAC Smear of metastatic deposits of papillary carcinoma of thyroid in lypmh node showing: papillary fragments of tumour cells

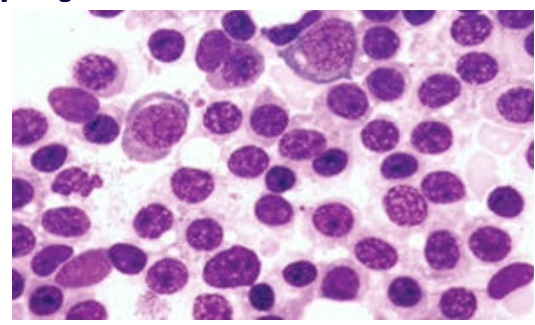

Figure: 4. FNAC Smear of Non Hodgkin lymphoma showing plasmablastic cells.
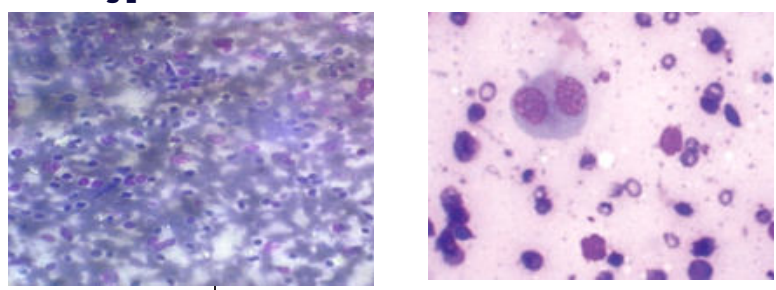

Figure: 5a.FNAC smear of Hodgkin lymphoma Showing: monomorphic tumour cells

Figure: 5 b. classic Reed-Sternberg cell

\section{Discussion}

The present study included 530 cases, clinically presented with palpable cervical lymphadenopathy and sent for cytological evaluation.

Out of total 53 malignant cases, $48(90.6 \%)$ cases were metastatic, 5(9.4\%) cases were lymphomas.

Among lymphomas 3(60\%) cases NHL and 2 (40\%) cases HL. Squamous cell carcinoma was the most common morphological type diagnosed in metastatic lymph nodes, followed by adenocarcinoma.

Similar findings were observed in studies done by Babu G S et al[5] and Steel et al[6].

\section{Conclusions}

Present study highlights the importance of FNAC. FNAC is a simple rapid cost effective in diagnosing patients presenting with cervical lymphadenopathy.

It also helps to diagnose malignancy in advanced stage patients based on the FNAC diagnosis these cases can be managed on palliative care thereby saving the patient from excision biopsy.

In many cases FNAC prove itself as a first investigation to clinch diagnosis in occult malignancy where there is no clinical suspicion.

It is also a good sensitive first line method in patients with suspected malignant cervical lymphadenopathy.

It plays an important role to confirm or exclude metastasis in a lymph node in a known case of malignancy there by avoiding unwanted surgery.

Funding: This research did not receive any specific grant from any funding agency in the public, Commercial or nonprofit organizations.

Ethical approval: The study was conducted after ethical approval by the Institutional Ethics Committee.

\section{REFERENCES}

1. Tilak V,Dhadel A V, Jain R. Fine needle aspiration cytology of the head and neck masses. Indian J pathol Microbiol 2002;45:23-9.

2. Bhargava P, Jain AK. Chronic cervical lymphadenopathy a study of 100 cases. Ind J Surg 2002;64:344-6.

3. Hafez NH, Tahoun NS. Reliability of fine needle aspiration cytology as a diagnostic tool in cases of cervical lymphadenopathy. I Egypt Natl Canc Inst.2011:23:105-14.

4. Koo V, Like TF, Spence R. fine needle aspiration cytology in the diagnosis of granulomatous lymphadenitis.Ulster Med J.2006 Jan;75(1):59-64.

5. Babu G S, Ramesh G, Kashyap B, Suneela S, Hiremath SS, Murgud S.Cytohistopathological evaluation of the cervical lymph nodes by fine needle aspiration cytology.J Carnio Max Dis 2014;3:101-5.

6. Steel BL, Schwart MR, Ramzy I. Fine needle aspiration biopsy in the diagnosis of Lymphadenopathy in 1103 patients. Role, Limitations and analysis of diagnostic pitfalls. Acta Cytol 1995;39:76-81. 